\title{
E A FOTOGRAFIA DO BURACO NEGRO, HEIN? ALIÁS, FOTO?
}

\author{
Por Henrique Romeo Guimarães ${ }^{1}$ \\ Professor de Física de Ensino Médio \\ (Secretaria de Estado de Educação do Distrito Federal) \\ okaiara@gmail.com
}

Recibido: 01/05/2019

Aprobado: 03/06/2019

\begin{abstract}
Nadja Simão Magalhães é Bacharel em Física pela Universidade de Brasília (1984), Mestre em Física das Partículas Elementares pela São Paulo (USP, 1987) e Doutora em Ciências pelo Instituto de Física da Universidade de São Paulo (1992). Desenvolveu pesquisas de pós-doutorado na USP, na Louisiana State University (EUA), no Instituto Nacional de Pesquisas Espaciais (São José dos Campos) e na University of Victoria (Canadá). É Professora no Departamento de Física da Universidade Federal de São Paulo, no campus de Diadema (SP). Recentemente iniciou colaborações envolvendo análise e processamento de sinais em fïsica aplicada, na temática de bioacústica de cetáceos com pesquisadores de biologia marinha. É membro da Sociedade Brasileira de Física, da The International Society on General Relativity and Gravitation, da International Union of Pure and Applied Physics, da Sociedade Portuguesa de Relatividade e Gravitação e da Sociedade Astronômica Brasileira.
\end{abstract}

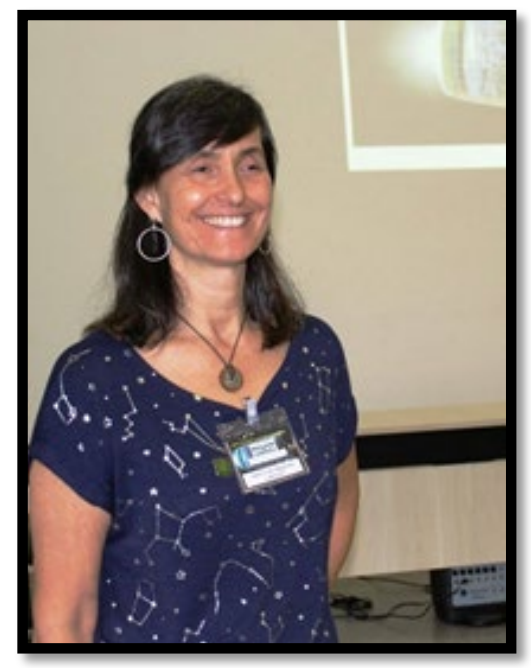

Figura 1. Profa. Nadja Simão Magalhães Crédito: Laura Belchior

No dia 10 de abril de 2019, às 10 h (horário de Brasília), foi finalmente divulgada a tão esperada fotografia do buraco negro (ou, imagem, como os cientistas preferiram chamá-la). A seguir, apresentamos a entrevista, em formato de bate-papo, realizada por Internet com a astrofísica e professora associada da UNIFESP, Nadja Simão Magalhães, que falou sobre os buracos negros e a imagem daquele localizado no centro da galáxia $M 87^{2}$ (Messier 87). Caso alguém queira apontá-lo no céu, procure a constelação de Virgem, próxima à constelação de Leão, entre as estrelas Spica e Regulus.

\footnotetext{
${ }^{1} \mathrm{O}$ autor da entrevista gostaria de agradecer aos seguintes colaboradores: Dr ${ }^{\mathrm{a}}$. Kelen Pizol, pelo auxílio em atendimentos pela Internet; Dr. Luveno Freitas, pela consultoria com hardware e software; Peterson Paim, pela orientação nos desafios com vídeos e com edição; Priscila e Nelson, pela recepção e carinho; Rafael Mafra, pela consultoria e sua valiosa experiência com o GugaCast; Prof. Samuel Amaral, pela consultoria em Filosofia da Ciência; Prof a . Thais Cyrino Forato, pela confiança e apoio.

${ }^{2}$ Para mais informações sobre a Galáxia M87, veja Messier 87 capturada pelo Very Large Telescope do ESO. Disponível em: https://www.eso.org/public/brazil/images/eso1907b/ Acesso em: 31 Jul. 2019.
} 


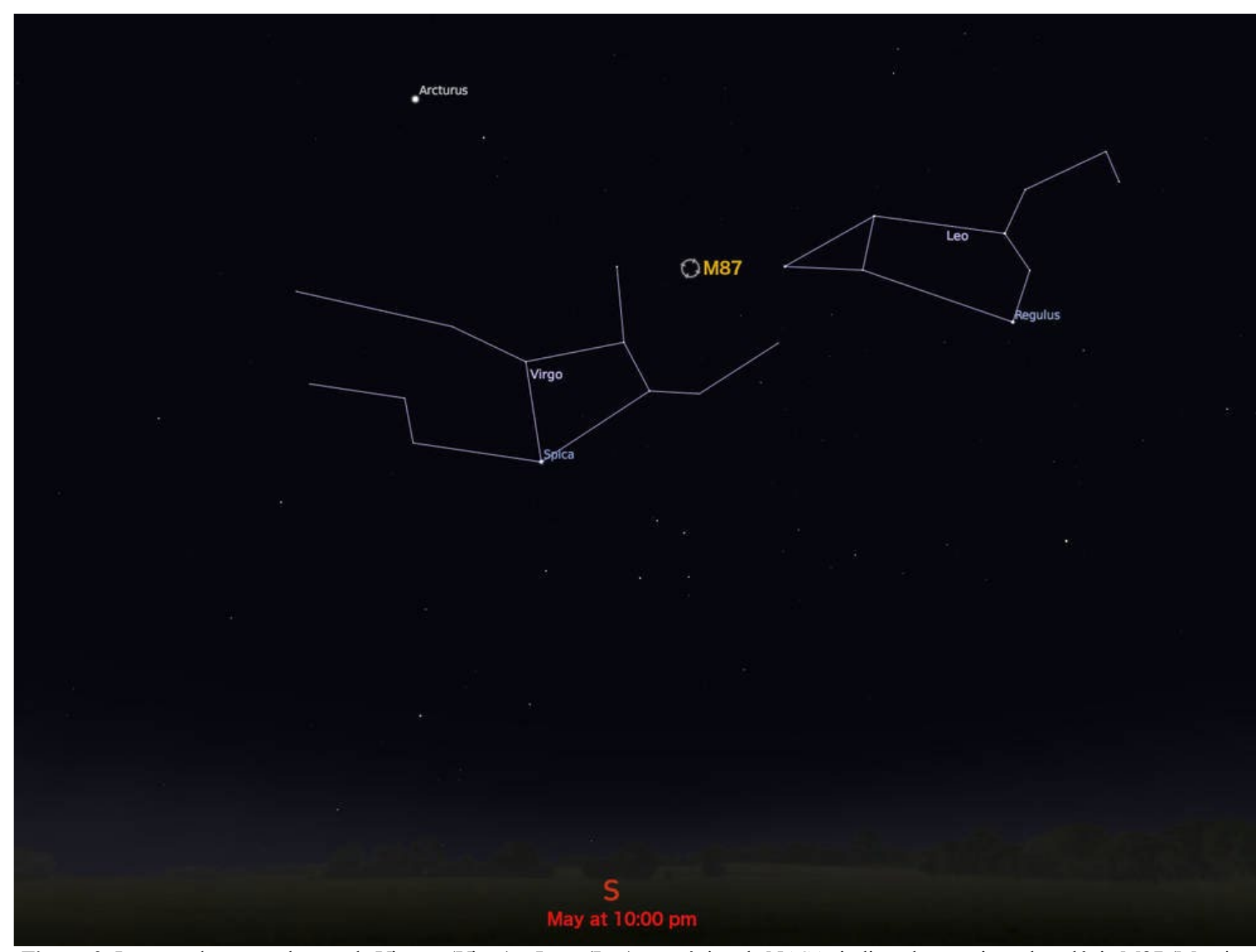

Figura 2. Imagem das constelações de Virgem (Virgo) e Leão (Leo), na página da NASA, indicando a posição da galáxia M87 (Messier 87), no centro da qual temos o buraco negro supermassivo observado pelo EHT. Crédito: NASA.

\section{Como podemos explicar para as pessoas o que é um buraco negro?}

Há um tempo, eu costumava explicar assim: "o buraco negro é uma estrela muito grande que foi se transformando" - já que as estrelas vão transformando seus elementos químicos internos em função da idade. Digamos que elas vão "queimando" todo o combustível que têm. E algumas, que são muito grandes, que são muito maiores que o nosso Sol, por exemplo, "queimam" o combustível de tal forma que vão colapsando para dentro delas mesmas. Os elementos vão se "apertando" e acontecem reações nucleares e, num certo momento, gera-se uma reação nuclear em cadeia e elas explodem completamente. Os gases e elementos leves são cuspidos para fora e viram aquelas nuvens maravilhosas que a gente vê nas imagens dos telescópios e...

\section{Supernovas, não é?}

Isso! Explosões de supernovas. E essas (que geram buracos negros) são supernovas especiais porque são muito, muito grandes, e o núcleo se aperta por conta dessa gravidade e se compacta. Dependendo do tamanho da estrela, o que vai sobrar é esse buraco negro. Então, o buraco negro é a fase final da vida de uma estrela; de uma estrela que era muito, muito grande. Assim eu costumava explicar. Mas, hoje em dia, depois de ter refletido um pouco, eu prefiro olhar o buraco negro de uma perspectiva um pouco diferente. Eu gosto de dizer que o buraco negro é uma fase da transformação de uma estrela: se você olhar o que resta em volta da estrela, que dizem que morreu, é uma coisa tão linda, que eu não consigo dizer que a estrela morreu! É claro que se você olhar só aquela coisinha pequenininha que sobrou no lugar da estrela, aquela massa dura que está esfriando (quando o que resta é, por exemplo, uma anã branca), é possível dizer que a estrela morreu. Mas você olha para fora, olha aquela nuvem maravilhosa que também restou da explosão e pensa: "Ela não morreu. Ela virou outra coisa". 


\section{Como a lagarta que virou a borboleta.}

É a analogia perfeita. Eu gosto mais dessa imagem; olhar essa continuidade cósmica e ver que o buraco negro é um remanescente de uma etapa da existência desse objeto que foi uma estrela, que nesse momento virou aquele buraco negro mais a nebulosa. Esse buraco negro é um objeto extremamente maciço e a massa dele é tão grande que atrai tudo que tem em volta, inclusive a luz. Teoricamente, vira uma singularidade [gravitacional], ou seja, toda a massa vai para um ponto. Resta aquele envoltório escuro do qual não está saindo luz. A gente chama o raio do buraco negro de Raio de Schwarzschild. O buraco negro é isso: uma estrela que se transformou.

\section{Vamos falar sobre a imagem do buraco negro, propriamente dita. Será que podemos chamá-la de "fotografia do buraco negro"?}

Quando a gente pergunta para os mais jovens o que é uma fotografia, eles mostram o celular. O que o celular faz? Ele pega os fótons, de fato, a radiação luminosa que bate na objetiva do celular, e aqueles fótons se transformam em sinais elétricos, que vão ser processados e salvos na memória do aparelho. Depois, quando você quer "revelar" as fotos, você liga numa impressora, aquele código se transforma novamente em corrente elétrica, que passa para a impressora que decodifica e manda as tintas imprimirem do jeito que está codificado. Isso é a fotografia. Nos primórdios da fotografia propriamente dita, que acontecia? Um fóton batia na lente, a lente fazia todos os caminhos ópticos para bater na placa fotográfica, aquela placa era levada cuidadosamente para um lugar para ser revelada, passava por um processo químico, a imagem aparecia e era passada para o papel: tinha que ser passado também quimicamente para o papel. Então, era um processo químico-físico. E essa era a fotografia. Então, vejo as pessoas perguntarem: "Isso é uma imagem ou é uma fotografia?". O que foi divulgado do buraco negro é uma imagem do buraco negro, que foi processada muito à moda das fotografias atuais, do que a gente, hoje, chama de fotografia. Foram recebidos sinais eletromagnéticos, fótons, daquele objeto que está lá no meio daquela galáxia por meio de vários radiotelescópios. Esses sinais foram para uma central e foram processados e, a partir desse processamento, foi gerada a imagem. Os cientistas desse conjunto de telescópios foram muito cautelosos em falar que aquela era uma imagem do telescópio, que ela foi processada digitalmente. Então, eu acho mais adequado você falar numa "imagem", que é como os cientistas a trataram.

\section{E o interessante é que parece que a radiação que foi utilizada, a onda que foi utilizada, não é onda da luz visível, certo?}

Não é!

\section{Elas são ondas de rádio.}

Exato.

7. Essas ondas de rádio seriam luz que o olho humano não enxerga, mas que os instrumentos foram capazes de "enxergar".

De detectar, digamos assim.

8. De tudo que você explicou, o que eu entendo é o seguinte: "Ah, será que eu posso chamar de 'foto' a imagem do buraco negro?" E aí, a resposta seria: "Bom, depende do que você quiser chamar de fotografia".

Sim, a terminologia mais precisa é essa: uma imagem. Eles conseguiram elaborar uma imagem, em cima do sinal elétrico que veio do sinal dos fótons, em cima do processamento. Eu, particularmente, fico com a terminologia dos colegas cientistas que chamam de imagem: é uma imagem. Acontece algo parecido com aquilo que costuma ocorrer com os conceitos da Quântica quando são apropriados por algumas pessoas. Por exemplo, essa coisa da imagem e foto... Algumas pessoas usam a palavra foto para fazer algo sensacionalista; e pode ser que seja isso mesmo, usam esse termo com essa finalidade. 
Eu não sei até que ponto isso é saudável ou vai confundir a cabeça das pessoas. Essa é uma primeira imagem, assim como o eclipse de Sobral ${ }^{3}$ foi uma primeira experiência sobre o encurvamento da luz, essa é a ponta do iceberg de outras que virão. Eu olho com muito respeito o esforço imenso que essa equipe fez e vejo com uma alegria muito grande para a humanidade como uma oportunidade de estar vendo isso aí. Inclusive, no dia que saiu a imagem, eu estava dando aula e era uma aula de Cálculo. Mas no começo da aula, eu falei: "Gente, eu preciso compartilhar isso com vocês"; "Gente, vocês estão vendo aqui uma coisa histórica, que vocês vão poder falar para seus netos. Vocês estão vendo a primeira imagem mais próxima possível do que pode ser um buraco negro que a humanidade está conseguindo captar". E foi assim. Os meus alunos acharam muito legal ver aquilo. Eu tentei passar para eles esse entendimento: da importância do evento e que isso é uma luz no fim do túnel, quer dizer, o começo de uma jornada que vai ser aperfeiçoada. E a gente utilizando terminologia adequada, à medida que as pessoas vão perguntando.

\section{Eu vou até evitar usar a palavra prova, vamos colocar a palavra evidência, que é uma palavra mais suave: a imagem do buraco negro que foi obtida pode ser considerada mais uma das várias evidências que já existem de que a Teoria da Relatividade de Einstein funciona, porque isso também tem sido uma espécie de "mantra" muito repetido em vários meios de comunicação: "A imagem do buraco negro provou..."; o que a gente está usando aqui é "evidenciou que Einstein estava certo".}

É. Essa pergunta é muito interessante, porque essa confusão é uma realidade. E eu digo confusão, porque o pessoal atribui a Einstein a descoberta dos buracos negros. Na verdade, Einstein tem o grande mérito de ter desenvolvido a Teoria da Relatividade Geral. E essa teoria gerou uma série de implicações e Einstein não é responsável por todas elas, absolutamente. Ele é responsável por uma, duas, três... Algumas dessas implicações. Por exemplo, a luz ter passado por aquela trajetória do eclipse de Sobral. Mas, os buracos negros, Einstein tem muito pouco a ver com os buracos negros em si. Os buracos negros vieram de uma solução das equações de Einstein e foram equações solucionadas pelo Schwarzschild, o que explica o nome do Raio de Schwarzschild. E, na época, eles nem sabiam o que era aquilo: é uma singularidade, que tem um raio... Parece que até o próprio Einstein não acreditava naquilo. Ele achava a ideia de "singularidade" muito estranha. A gente vive num momento da nossa História humana em que "a propaganda é a alma do negócio", como dizem as pessoas. Então, acabam pegando ícones da Ciência, no caso, o Einstein, para tratar de um assunto que, se você falar que foi Schwarzschild, as pessoas nem vão escutar, entendeu? Mas você tem que falar "olha, foi o Schwarzschild". Inclusive, o Schwarzschild, quando resolveu a equação de Einstein, na época da Primeira Guerra Mundial, ele estava nas trincheiras ${ }^{4}$. Tem toda uma história bacana que o grande público não conhece. Então, essa imagem tem muito a ver com o que é modelado do buraco negro a partir das equações de Einstein; isso é fato. Os buracos negros já eram pensados como existentes antes dessa imagem, por conta daqueles movimentos das estrelas no centro da Via Láctea ${ }^{5}$. Essa imagem é mais uma evidência que se soma à existência de buracos negros; ela pode fortalecer a Teoria da Relatividade Geral. Agora, a forma como ela [a imagem do buraco negro] vai fortalecer a Teoria da Relatividade Geral é a seguinte: se, ao longo do tempo, nas próximas pesquisas, o que foi modelado com essa imagem se confirmar, será algo assim: a partir da Relatividade Geral como referência, esse buraco negro deve ter o raio tal, a massa tal, e deve estar girando de tal maneira. Então, nesse caso, é um dado importante. Se a Relatividade estiver certa e esse buraco negro é assim, vamos ver quais são

\footnotetext{
${ }^{3}$ Sobre o eclipse de Sobral e a comemoração de seus 100 anos, veja: Eclipse de Sobral 100 anos. Disponível em: http://www.mast.br/sobral/eclipse.html Acesso em: 31 Jul. 2019; Sobral - 100 anos do eclipse de Sobral e a comprovação da Teoria da Relatividade Geral. Disponível em: http:/www.on.br/eclipse-sobral/documentario/ Acesso em: 31 Jul. 2019; e, ainda, Crispino, Luís C. B. and Kennefick, Daniel J.. A hundred years of the first experimental test of general relativity. Nature Physics. V. 15, May 2019, 416-419 p. Disponível em: https://doi.org/10.1038/s41567-019-0519-3

${ }^{4}$ Para saber mais sobre Schwarzschild ver: SAA, Alberto. Cem anos de buracos negros: o centenário da solução de Schwarzschild. Rev. Bras. Ensino Fís., São Paulo, v. 38, n. 4, e4201, $2016 . \quad$ Disponível em http://www.scielo.br/scielo.php?script=sci arttext\&pid=S1806-11172016000400301\&lng=pt\&nrm=iso acessos em 31 jul. 2019. Epub 10-Out-2016. http://dx.doi.org/10.1590/1806-9126-RBEF-2016-0191.

${ }^{5}$ Esse movimento está no vídeo Stars orbiting the black hole at the heart of the Milky Way do canal European Southern Observatory (ESO). Disponível em: https://www.youtube.com/watch?v=TF8THY5spmo Acesso em: 31 Jul. 2019.
} 
as implicações: se ele tem essa massa e essas características, isso vai se refletir no entorno dele; aí os astrônomos vão poder observar, coletar dados e fazer comparações que não dependem da Relatividade Geral. Então, vão ser novas maneiras de testar a Relatividade Geral. Essa imagem é muito importante, tanto para ir consolidando a ideia de existência dos buracos negros, como um teste da Relatividade Geral, no limite do que a gente chama de Campo Forte, onde a Gravitação é muito intensa.

10. Na verdade, é uma foto (ou uma imagem) da sombra do horizonte de eventos. Quer dizer, se a estrutura ao redor do horizonte de eventos emitisse radiação, emitiria ondas de rádio. Há quem diga: "Na verdade, é a imagem da sombra". Por que que se fala dessa forma?

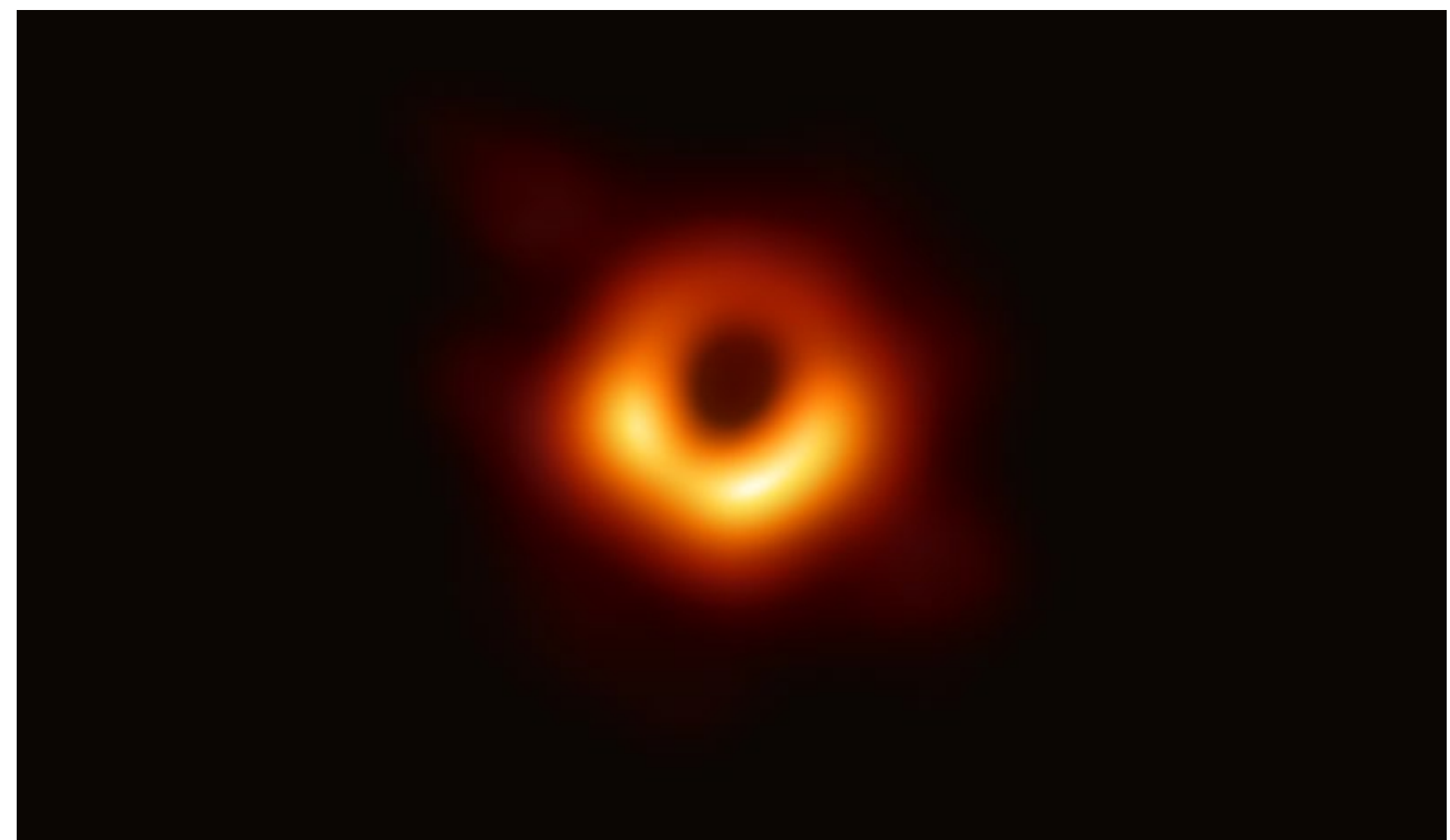

Figura 3. Imagem da sombra do buraco negro no centro da galáxia Messier 87. Crédito: Event Horizon Telescope Collaboration

O que está acontecendo em volta do buraco negro é uma coisa muito complexa, na verdade. O buraco negro não está sozinho no espaço. Ele está envolto por uma capa de gás, provavelmente daquela estrela que explodiu e da qual ele mesmo se originou. E tudo indica que ele deve estar rodando. Essas partículas que rodam em torno dele, aceleradas, emitem radiação. E se você imaginar um buraco negro sem nada em volta, só o buraco negro, você não vê nada. Então, o que você acaba vendo é o contorno do buraco negro, envolvido por aquele gás que está irradiando. Você enxerga a radiação, inclusive são várias cores: é mais amarelo de um lado, mais vermelho do outro, porque são velocidades diferentes da radiação que é emitida por causa da rotação. Por isso que se acredita que ele esteja rodando, inclusive, porque tem essa diferença de cores e de espessura. Além disso, por causa da própria gravidade, a radiação vem de uma forma encurvada, ele faz uma lente gravitacional, como a gente chama. Naquele envoltório, você não está observando nada com extrema definição. Quer dizer, a trajetória do gás é entortada pela curvatura do espaço-tempo devida ao buraco negro. Então, eu acredito que a ideia da sombra está relacionada com o fato de que você não está vendo o buraco negro desenhado, está vendo aquela parte escura, que não foi ocultada pela radiação emitida por esse movimento todo de rotação.

\section{Em outras palavras..。}

Se você pensar em sombra também, é estranho você falar de "sombra de uma coisa escura", que sombra é essa que a gente está vendo? A gente está vendo, na verdade, através da lente gravitacional, os gases, toda aquela dinâmica, encurvada. Do buraco negro, sem luz, só resta ver sua silhueta escura a "sombra". 
12. Aliás, tem até gente que gosta de fazer o preciosismo de falar assim: "Não! Você não pode falar que a imagem é fotografia do buraco negro, porque o buraco negro não emitiria luz, por definição". Só que se você fotografar um buraco comum, por exemplo, um buraco na rua que está escuro, não emite luz, porém, o contexto dele permite que seja fotografado.

Pois é!

13. Uma vez, tentaram me explicar o que seria a singularidade [gravitacional]: "Ah! Singularidade é dividir por zero!"; e eu pensei: "O que você está falando é que meu professor de Matemática lá da escola estava errado! Quem é você para falar que meu professor de Matemática estava errado? Ele me ensinou que não pode dividir por zero!". Eu acho que não deve ser bem isso...

A ideia de ser singularidade é uma singularidade espacial. É você conseguir colocar toda a massa de uma estrela num ponto. E essa ideia é um resultado matemático, porque quando você tem as equações com a simetria esférica, em uma esfera, o centro dela é uma coisa pontual, não tem uma forma.

\section{Então, a gente pode falar que a singularidade [gravitacional] tem uma densidade infinita?}

Dá! Dá para dizer isso sim.

\section{Ah! Então, a pessoa me falou corretamente! Dividir por zero! ${ }^{6}$}

Essa singularidade [gravitacional] incomodava Einstein. Ele achava que a Natureza não ia fazer uma coisa dessas. $O$ fato é que a gente não consegue ver dentro do buraco negro, então, não sei se a gente vai conseguir ter uma resposta tão cedo de como ele, de fato, é lá dentro. Porque nada consegue sair...

16. A dúvida que está me ocorrendo agora é a seguinte: será que você falar que a matéria se concentra num ponto é apenas uma comodidade no tratamento matemático do modelo do buraco negro ou a teoria realmente torna necessário que você modele de tal forma que a matéria fique num ponto?

A teoria torna necessário que a matéria fique num ponto. A solução da teoria conduz a isso. Toda a matéria submetida à Gravitação vai para um ponto. Essa é a noção do buraco negro.

17. Se eu tentar modelar teoricamente um buraco negro de forma que a matéria fique num espaço muito pequeno, mas que é maior do que um ponto, aí, a teoria não funciona?

Não funciona, porque se você tem a matéria que consegue ficar fora de um ponto, significa que ela tem um volume, então, você tem que ter componentes ali; você tem que ter componentes que estão vencendo a Gravidade e o buraco negro é esse caso limite em que o componente não consegue vencer a Gravidade e, aí, vai tudo para aquele ponto. Pode até ser uma abstração, uma maneira pela qual a gente modela dessa forma hoje; mas, por enquanto, não tem outra forma de enxergar isso. Matematicamente, não tem.

18. Então, se Einstein ficou chateado com a incerteza da Física Quântica falando que "Deus não joga dados", quer dizer, Ele joga os dados e, ainda por cima, esmaga muito esses dados.

Ele também não gostou dessa coisa apertada no buraco negro. Mas, ainda bem que outras pessoas pegaram as equações que ele introduziu, solucionaram e foram achando outras evidências, outros

\footnotetext{
${ }^{6}$ Lembramos que a densidade de um objeto é, por definição, a razão entre sua massa e o volume que esse objeto ocupa no espaço. Após explodir como Supernova, caso o núcleo restante da explosão da estrela tenha massa suficientemente grande, esse núcleo passa a reduzir o seu volume devido à ação da própria gravidade da massa desse núcleo, fazendo-o reduzir seu volume sem que haja uma força interna "de fornalha" capaz de se opor a isso. Esse volume irá se reduzir mais e mais. Como a densidade depende da massa desse "caroço" e essa será sempre finita, na medida que o volume for tendendo a zero, então a densidade $\mathrm{D}=\mathrm{m} / \mathrm{V}$ terá valores cada vez maiores, aumentando sem limite, isto é, divergindo para o infinito.
} 
fenômenos e, entre eles, está o buraco negro. Por isso que é legal fazer jus aos outros cientistas que vieram depois de Einstein e acreditaram nesse fenômeno. Continuaram pesquisando e hoje temos várias evidências do buraco negro, observacionais, inclusive.

19. Quase todo mundo que vê a imagem do buraco negro, vê a imagem de uma "rosquinha", uma assimetria na luminosidade, esse anel luminoso.

Essa assimetria é bem legal, inclusive, porque a explicação é que o buraco negro não está parado, ele está rodando. No que ele roda, ele arrasta a matéria e quando a matéria carregada com carga elétrica é acelerada, ela irradia. Então, quando está irradiando na nossa direção, vai jogar a luminosidade de uma forma; quando está rodando para o outro lado, a radiação é para o outro lado. Então, essa assimetria é justamente por causa da diferença, da quantidade e da qualidade da radiação para cada lado do giro da matéria.

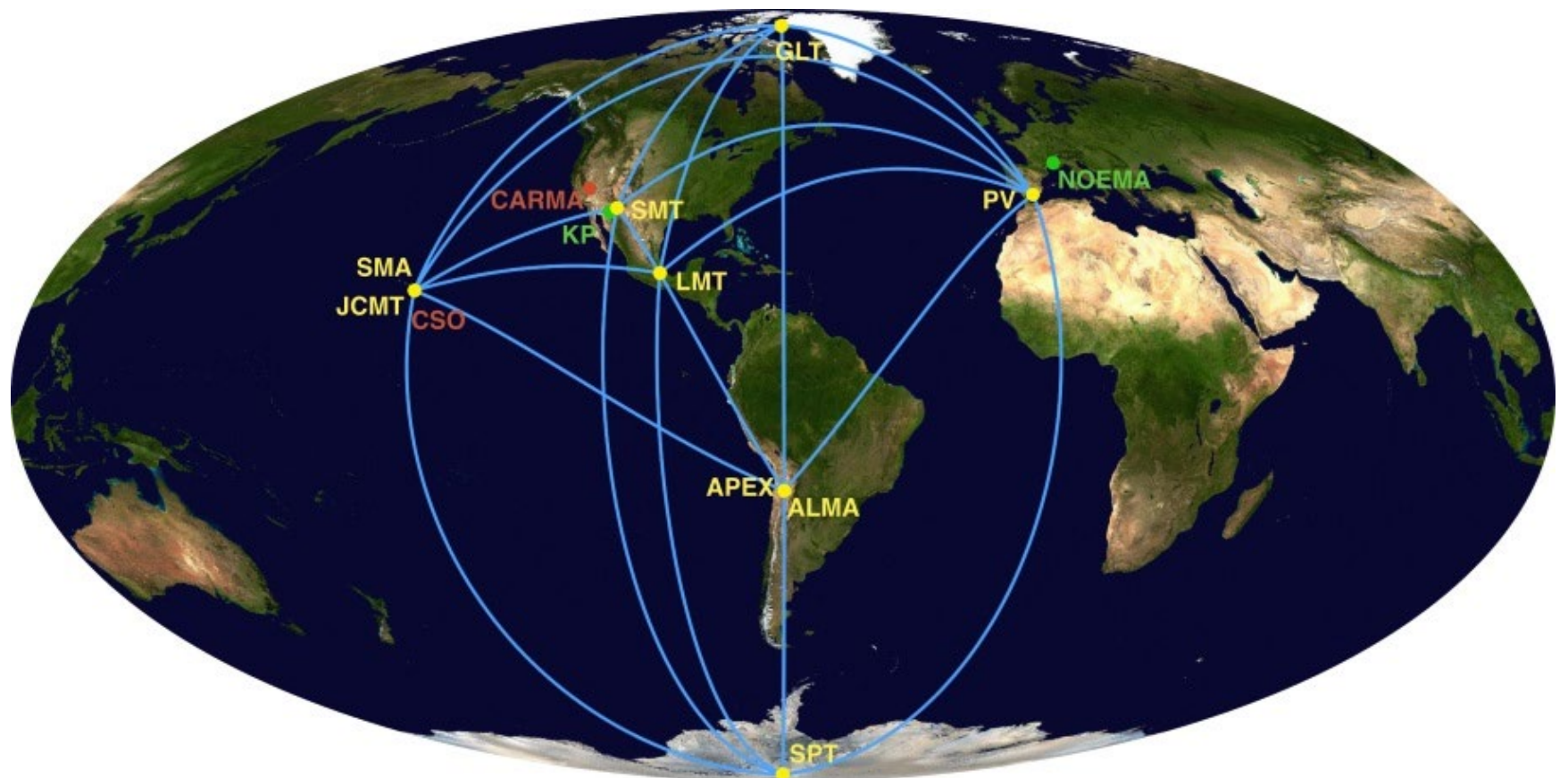

Figura 4. Figura do globo terrestre indicando as posições dos telescópios espalhados pela Terra que integraram o EHT, criando um telescópio virtual com raio próximo ao da Terra, para capturarem os dados provenientes do buraco negro supermassivo da galáxia M87.

Crédito: The Astrophysical Journal Letters ${ }^{7}$.

20. Eu percebi que as pessoas ficaram bastante céticas em relação à validade da "captura" da imagem que foi processada. Foi usada aquela técnica que o pessoal chama de técnica de interferometria, de colocar diferentes estações de telescópios em diferentes partes da Terra para poder conseguir montar o Telescópio do Horizonte de Eventos (EHT). Então, é uma técnica bastante complexa, sofisticada, que exige um algoritmo e eu também ouvi gente falar: "Nossa! Será então que é tipo um Photoshop?" Eu vi as pessoas ficarem na dúvida: "Como é que eu vou saber se a imagem é completada por um algoritmo, se essa imagem é confiável?" Várias estações diferentes para poder juntar esses dados espalhados e, depois, compor essa imagem, tem um algoritmo complicado por trás, quer dizer, será que do ponto de vista epistemológico, será que haveria chance de que a imagem obtida fosse uma imagem inesperada pela teoria, por exemplo? Será que o Princípio [ou critério] de Falseabilidade da Ciência teria chance de operar no caso dessa imagem? Será que essa imagem é honesta do ponto de vista do jogo científico? A gente lembra daquele episódio histórico ${ }^{8}$ que aconteceu

\footnotetext{
${ }^{7}$ The Event Horizon Telescope Collaboration. First M87 Event Horizon Telescope Results. II. Array and Instrumentation. The Astrophysical Journal Letters. V. 875, N. 1, 10 Abr. 2019 . Disponível em: https://iopscience.iop.org/article/10.3847/2041-8213/ab0c96 Acesso em: 31 jul. 2019.

${ }^{8}$ Para conhecer alguns aspectos relacionados a essas questões, ver Chalmers, Alan. O significado e o caráter problemático dos dados de Galileu sobre o telescópio. In: Chalmers, Alan. A fabricação da Ciência. São Paulo: Editora Unesp, 1994.
} 
com Galileu, quando os adversários de Galileu ficaram questionando se eles poderiam confiar na imagem que o telescópio de Galileu mostrava...

Essa é uma dúvida que eu acho muito saudável na Ciência, sabe? Porque a gente não pode acreditar só porque alguém falou. Tem que ver evidências que dão substância àquilo que a pessoa está falando. No caso dessa imagem, realmente foi feita com menos de dez telescópios, mas foi construída ao longo de vários dias; então, foi coletado um número muito grande de dados, mas a imagem realmente não era completa, tinha buracos, porque os telescópios não conseguiam varrer todo o espaço, pegar todo o sinal; mas a técnica usada computacionalmente para obter a imagem foi muito hábil, foram algoritmos muito bem feitos, no sentido de que eles utilizaram técnicas de montagem de imagens a partir de poucas informações. Eles testaram essa técnica com imagens terrestres. Então, por exemplo, pega essa minha imagem e pega somente dez dados da minha imagem, dez pedacinhos da minha imagem, e o algoritmo era tão sofisticado que eles conseguiam processar e montar a minha imagem muito próxima do que ela é, do que você está vendo, por exemplo. Então, eles não fizeram isso aleatoriamente, do nada. Eles fizeram muitos testes com esse algoritmo. Agora, eles são cuidadosos (os cientistas que fizeram isso) a ponto de dizer que a imagem montada é a imagem mais provável, que tem uma forte probabilidade, uma boa probabilidade de ser uma imagem que corresponda ao objeto que eles visaram. E, ao montar essa imagem, eles não usaram a Teoria da Relatividade. Eles usaram apenas montagem computacional mesmo. Não é justo dizer que foi Photoshop, porque o Photoshop pega a imagem que existe e altera. Não! Eles pegaram os mínimos dados que tinham e, com base na teoria de imagens, não deduziram, mas refizeram da seguinte maneira: imagina a pessoa que faz a restauração de uma obra de arte muito antiga, papiro egípcio, por exemplo. Se for possível fazer isso, a pessoa vai lá com toda paciência, tirando e vendo qual é o elemento químico encontrado. Aí, completa a cor. Você tem a obra terminada, melhorada. E será que você tem certeza que aquela é a cor que o pintor pintou? Você diz: "Eu não tenho certeza absoluta, mas dentro do meu melhor conhecimento, essa é a mais provável". E se você pega uma pessoa competente, experiente e séria, você vai dizer: "De fato, esse é o melhor que a gente pode ter". E eu acredito que essa equipe fez exatamente isso. Pegaram ótimas pessoas do mundo inteiro, com telescópios do mundo inteiro, pegaram sistemas de processamento de algoritmo de última geração e fizeram o melhor trabalho que podiam fazer, nesse momento. Eu acho que deve estar bem parecido com o que seria detectado por um hipotético telescópio do tamanho da Terra. Pode estar um pouco borrado, pode ter uma incerteza, mas o "jeitão" está lá...

\section{Ou seja: fizeram Ciência!}

Exato.

22. O que é a Ciência? Nós nos baseamos nos fatos que temos, nos dados que temos e fazemos o melhor possível para nos aproximar da realidade.

Exatamente. 